\title{
Investigating Respondents and Nonrespondents of a Postal Breast Cancer Questionnaire Survey Regarding Differences in Age, Medical Conditions, and Therapy
}

\author{
Anna Lia Frobeen ${ }^{a}$ Christoph Kowalski ${ }^{a} \quad$ Verena Weiß $^{b}$ Holger Pfaff ${ }^{a}$ \\ a IMVR - Institute of Medical Sociology, Health Services Research and Rehabilitation Science at the Faculty of Human Sciences and the \\ Faculty of Medicine of the University of Cologne, Cologne, Germany; \\ bIMSIE - Institute of Medical Statistics, Informatics and Epidemiology of the University of Cologne, Cologne, Germany
}

\section{Keywords}

Questionnaire survey · Nonrespondent · Bias · Breast cancer

\section{Summary}

Background: Collecting patient-reported data via postal questionnaires is a common and frequently used technique. Selection bias may occur through lost data from nonrespondents. This study investigated differences in characteristics between respondents and nonrespondents of a postal breast cancer survey. Patients and Methods: The investigation was based on a cross-sectional postal questionnaire survey for the mandatory annual routine (re-)certification of accredited breast centers in North Rhine-Westphalia in 2010. Out of 4,444 patients meeting the inclusion criteria who gave their consent to participate, 3,856 respondents sent back a questionnaire and 588 nonrespondents did not. Using logistic regression, differences between respondents and nonrespondents regarding information gathered through hospital staff concerning age, affected breast, UICC (Union for International Cancer Control) staging and grading, ASA (American Society of Anesthesiologists) classification, neoadjuvant chemotherapy, and type of surgery were assessed. Results: Very young and very old patients sent back their questionnaire significantly less frequently, as did patients who showed a later cancer stage and poorer general health and those who underwent mastectomy. Conclusion: Differences exist between respondents and nonrespondents with regard to age, disease, and therapy characteristics that need to be considered for the interpretation and generalizability of survey results due to selection bias.

(c) 2016 S. Karger GmbH, Freiburg

\section{Introduction}

Postal questionnaire surveys are a widely used instrument for acquiring patient-reported data for scientific research purposes. Several quality criteria of a questionnaire survey have to be taken into account, especially a representative sample of the target population and a sufficiently high response rate, to ensure the generalizability of the results found within the sample $[1,2]$. Both the quantitative consideration of the response rate and a qualitative analysis of the nonrespondents are of vital importance for the quality of a survey because a loss of certain subgroups may result [2-4]. This kind of selection may lead to systemic differences and biases, such that the representativeness of the outcome is influenced as certain features of the sample are not equally gathered which may limit the generalizability of results [3-7]. The reasons for nonresponse are diverse in systemic and individual ways, but questionnaire surveys often have a higher nonresponse rate compared to other types of surveys $[3,8]$. Unfortunately, in most cases, only a little information is known about the process of dropout because these data are not explicitly collected, which is why nonresponse studies are usually difficult to implement $[2,3,9]$.

In previous studies, survey respondents and nonrespondents have been compared concerning diverse characteristics. Differences in age, sociodemographic status, health-related behavior, and health status were frequently found [5, 10-23]. Associations with higher age, lower education level, living alone, unfavorable health behaviors, and worse health status were found among nonrespondents. In contrast, some studies state no or only little differences between respondents and nonrespondents, and a few describe better health or sociodemographic characteristics to be associated with nonresponse [24-27]. However, only few data have been published about nonresponse comparisons in breast cancer populations. The authors of these studies found higher disease stages, more invasive surgery, and older age to be associated with a lower response rate.

\section{KARGER}

Fax +497614520714 (c) 2016 S. Karger GmbH, Freiburg

1661-3791/16/0112-0139\$39.50/0
Anna Lia Frobeen

IMVR - Institute of Medical Sociology, Health Services and Rehabilitation Science University of Cologne

Eupener Str. 129, 50933 Köln, Germany

Annalia@gmx.de 
Table 1. Characteristics of the study population

\begin{tabular}{|c|c|c|c|c|}
\hline Variable & $\begin{array}{l}\text { Respondents } \\
(\mathrm{n}=3,840,86.8 \%), \\
\mathrm{n}(\%)^{\mathrm{a}}\end{array}$ & $\begin{array}{l}\text { Nonrespondents } \\
(\mathrm{n}=585,13.2 \%), \\
\mathrm{n}(\%)^{\mathrm{a}}\end{array}$ & $\begin{array}{l}\text { Total } \\
(\mathrm{n}=4,425,100 \%) \\
\mathrm{n}(\%)^{\mathrm{a}}\end{array}$ & $\mathrm{p}$ value \\
\hline Age group & & & & $<0.0001$ \\
\hline Missing & 8 & 80 & 88 & \\
\hline $18-39$ years & $136(82.4)$ & $29(17.6)$ & $165(100)$ & \\
\hline $40-49$ years & $644(91.3)$ & $61(8.7)$ & $705(100)$ & \\
\hline $50-59$ years & $1,060(89.8)$ & $120(10.2)$ & $1,180(100)$ & \\
\hline $60-69$ years & $1,147(90.1)$ & $126(9.9)$ & $1,273(100)$ & \\
\hline $70-79$ years & $676(86.4)$ & $106(13.6)$ & $782(100)$ & \\
\hline 80 years and older & $169(72.8)$ & $63(27.2)$ & $232(100)$ & \\
\hline Affected breast & & & & 0.124 \\
\hline Missing & 162 & 22 & 184 & \\
\hline Right & $1,764(86.6)$ & $273(13.4)$ & $2,037(100)$ & \\
\hline Left & $1,823(87.2)$ & $268(12.8)$ & $2,091(100)$ & \\
\hline Both & $91(80.5)$ & $22(19.5)$ & $113(100)$ & \\
\hline UICC staging & & & & $<0.0001$ \\
\hline Missing & 686 & 119 & 805 & \\
\hline Stage 0 & $157(92.9)$ & $12(7.1)$ & $169(100)$ & \\
\hline Stage I & $1,403(89.8)$ & $159(10.2)$ & $1,562(100)$ & \\
\hline Stage II & $1,110(85.2)$ & $193(14.8)$ & $1,303(100)$ & \\
\hline Stage III & $351(82.4)$ & $75(17.6)$ & $426(100)$ & \\
\hline Stage IV & $133(83.1)$ & $27(16.9)$ & $160(100)$ & \\
\hline Grading & & & & 0.562 \\
\hline Missing & 418 & 52 & 470 & \\
\hline G1 & $572(87.3)$ & $83(12.7)$ & $655(100)$ & \\
\hline G2 & $1,994(86.7)$ & $306(13.3)$ & $2,300(100)$ & \\
\hline G3 & $856(85.6)$ & $144(14.4)$ & $1,000(100)$ & \\
\hline ASA classification & & & & $<0.0001$ \\
\hline Missing & 311 & 37 & 348 & \\
\hline 1 (normal health) & $1,734(89.1)$ & $212(10.9)$ & $1,946(100)$ & \\
\hline 2 (mild systemic disease) & $1,484(86.3)$ & $235(13.7)$ & $1,719(100)$ & \\
\hline $\begin{array}{l}\text { 3-5 (severe systemic disease to } \\
\text { moribund) }\end{array}$ & $311(75.5)$ & $101(24.5)$ & $412(100)$ & \\
\hline Neoadjuvant chemotherapy & & & & 0.858 \\
\hline Missing & 257 & 26 & 283 & \\
\hline Received & $264(86.8)$ & $40(13.2)$ & $304(100)$ & \\
\hline Not received & $3,319(86.5)$ & $519(13.5)$ & $3,838(100)$ & \\
\hline Type of surgery & & & & $<0.0001$ \\
\hline Missing & 270 & 37 & 307 & \\
\hline Mastectomy & $929(81.6)$ & $210(18.4)$ & $1,139(100)$ & \\
\hline Breast conserving & $2,641(88.7)$ & $338(11.3)$ & $2,979(100)$ & \\
\hline
\end{tabular}

Yet, some studies found little or no difference between respondents and nonrespondents [28-31].

The aim of this study was to explore differences regarding age, medical conditions, and therapy between respondents and nonrespondents of a postal questionnaire survey among breast cancer patients. This is of importance because of the notable scientific relevance of questionnaire surveys on the one hand and breast cancer as the most frequent malignant tumor disease among women on the other hand [32]. In detail, this study investigated if respondents and nonrespondents differed regarding the attributes of age, affected breast, UICC (Union for International Cancer Control) staging and grading, ASA (American Society of Anesthesiologists) classification, neoadjuvant chemotherapy, and type of surgery.

\section{Patients and Methods}

Design and Measurement Methods

For the present investigation, data based on a large-scale cross-sectional survey was analyzed as a substudy. The recruitment of patients within the main study took place in the context of the mandatory annual routine (re-)certification of accredited breast centers in North Rhine-Westphalia in 2010, which involved 52 breast centers covering 93 hospitals. The Cologne Patient Questionnaire for Breast Cancer (CPQ-BC) was used for this purpose. This instrument assesses the patients' perception on hospital organization, interaction with staff, quality of the accommodation, quality of information provided about the treatment and psychosocial support, and overall satisfaction. In addition, health-related quality of life, sociodemographic, and therapy information of the patients was collected [33].

Hospitalized patients who met the inclusion criteria were asked to participate in the survey. The inclusion criteria covered all patients who had under- 
gone surgery for primary breast cancer during their current hospitalization in a North Rhine-Westphalian breast center between 02/01/2010 and 07/31/2010 and for whom a definitive diagnosis and at least 1 postoperative histology were confirmed. There were no explicit exclusion criteria. Those who consented were mailed the questionnaire within 1 week of being discharged. After providing consent, additional medical and therapeutic information about all participants was gathered by the hospital staff and sent to the institution conducting the research.

The study was evaluated positively by the ethical review committee of the Cologne University Hospital and was conducted according to the Total Design Method by Dillman [34] with 3 contacts. Further details about the mandatory annual routine (re-)certification of accredited breast centers in North RhineWestphalia are reported in a publication by Kowalski et al. [35].

\section{Study Population}

Out of 4,944 patients, 4,444 gave their approval to participate in the study. 3,856 persons returned a completed questionnaire to the conducting institute and 588 did not, resulting in a response rate of $87 \%$. All 19 male participants were excluded from this analysis. The study population thus consisted of 4,425 patients, subdivided into 3,840 respondents and 585 nonrespondents.

\section{Statistics}

To compare respondents with nonrespondents, the variables age group (18$39,40-49,50-59,60-69,70-79$, and 80 years and older), affected breast (right, left, both), UICC staging (0-IV), grading (G1-3), ASA classification (1-5), neoadjuvant chemotherapy (yes/no), and type of surgery (breast-conserving, mastectomy) were investigated. The analysis of these variables included counts and percentages as well as a chi-square test. The variables which were statistically significant in bivariate tests were then included in a logistic regression model to obtain odds ratios with $95 \%$ confidence intervals. The p values of the Wald test were also provided. The significance level was set to $\alpha=0.05$, meaning a p value $<0.05$ was regarded as statistically significant. All p values were two-sided. Missing data was not imputed due to the explorative character of the study. The data was analyzed using the statistical software IBM SPSS Statistics 22 (IBM Corp., Armonk, NY, USA).

\section{Results}

The characteristics of the study population are presented in table 1. Significant bivariate differences $(\mathrm{p}<0.05)$ between the group of respondents $(3,840,86.8 \%)$ and the group of nonrespondents $(585,13.2 \%)$ were observed for the variables age group, UICC staging, ASA classification, and type of surgery. Higher proportions of nonrespondents were found in very young and very old patients, those with later disease stages and more severe comorbidity, and among patients having undergone mastectomy. These significant variables were included as independent variables in a logistic regression analysis to investigate the specific differences of both groups using odds ratios. The logistic regression model was based on 3,312 patients providing complete information on all 4 of these variables. The reference category of the dependent variable was set to 'questionnaire returned: yes'.

The results are presented in table 2 which lists the odds ratios for the independent variable subitems referring to the following reference categories: '60-69 years,' 'stage I', 'ASA 1', and 'breastconserving'. $95 \%$ confidence intervals are presented in brackets. The $\mathrm{p}$ value of the Wald test displays the statistically significant subitems which included age group ' $18-39$ years' $(p=0.019)$ and ' 80 years and older' $(\mathrm{p}=0.002)$, UICC 'stage II' $(\mathrm{p}=0.040)$ and 'stage
Table 2. Results of the logistic regression analysis of respondents and nonrespondents $(\mathrm{n}=3,312)$

\begin{tabular}{|c|c|c|}
\hline Independent variable ${ }^{a}$ & $\begin{array}{l}\text { Odds ratio (95\% confidence } \\
\text { interval) }\end{array}$ & $\mathrm{p}$ value \\
\hline \multirow{2}{*}{\multicolumn{3}{|c|}{$\begin{array}{l}\text { Age group } \\
\text { (reference '60-69 years') }\end{array}$}} \\
\hline & & \\
\hline $18-39$ years & $1.919(01.111 ; 3.316)$ & 0.019 \\
\hline $40-49$ years & $1.008(0.697 ; 1.459)$ & 0.965 \\
\hline $50-59$ years & $1.099(0.807 ; 1.495)$ & 0.550 \\
\hline $70-79$ years & $1.325(0.964 ; 1.822)$ & 0.083 \\
\hline 80 years and older & $2.047(1.308 ; 3.204)$ & 0.002 \\
\hline \multicolumn{3}{|l|}{$\begin{array}{l}\text { UICC staging } \\
\text { (reference 'stage I') }\end{array}$} \\
\hline Stage 0 & $0.791(0.426 ; 1.468)$ & 0.457 \\
\hline Stage II & $1.309(1.013 ; 1.691)$ & 0.040 \\
\hline Stage III & $1.458(1.026 ; 2.071)$ & 0.035 \\
\hline Stage IV & $1.331(0.811 ; 2.186)$ & 0.258 \\
\hline \multicolumn{3}{|l|}{$\begin{array}{l}\text { ASA classification } \\
\text { (reference 'ASA 1') }\end{array}$} \\
\hline ASA 2 & $1.195(0.929 ; 1.538)$ & 0.166 \\
\hline ASA 3-5 & $1.947(1.366 ; 2.776)$ & $<0.001$ \\
\hline \multicolumn{3}{|c|}{$\begin{array}{l}\text { Type of surgery } \\
\text { (reference 'breast conserving') }\end{array}$} \\
\hline \multicolumn{3}{|c|}{ Mastectomy } \\
\hline & $1.351(1.054 ; 1.733)$ & 0.018 \\
\hline
\end{tabular}

III' ( $\mathrm{p}=0.035)$, ASA ' $3-5$ ' ( $\mathrm{p}<0.0001)$, and type of surgery 'mastectomy' $(\mathrm{p}=0.018)$.

Logistic regression analysis showed that very young (18-39 years) patients and patients older than 80 years sent back their questionnaires significantly less frequently than the reference category '60-69 years', as did patients with higher disease stages (II and III) compared to the reference category 'stage I', patients categorized as ASA 3-5 representing a worse physical health status compared to the reference category 'ASA 1', and patients who had undergone mastectomy compared to less invasive 'breast-conserving' surgery.

\section{Discussion and Conclusion}

In this cross-sectional investigation of a postal questionnaire survey conducted in the North Rhine-Westphalian breast centers, respondents and nonrespondents were compared regarding differences in age, medical conditions, and therapy. The results show that statistically significant differences exist between both groups. Very young (18-39 years old) and very old ( $>80$ years old) patients returned their questionnaires significantly less often compared to patients aged between 60 and 69 years. An explanation could be the higher psychological burden of falling ill at a young age on the one hand and a lack of cognitive and physical efficiency at an older age on the other hand. The higher rate of advanced disease stages (UICC stage II and III) compared to a lower stage (UICC stage I) and more morbid patients (ASA 3-5) compared to healthier pa- 
tients (ASA 1) among nonrespondents may be associated with aspects of the practical realization of completing a written questionnaire. Reduced mobility and more intensive therapies with more restrictions and limitations together with longer exposure times may be some of the reasons. Regarding the type of surgery, nearterm follow-up hospitalizations and assumably higher psychological burdens may follow after mastectomy with the result that questionnaires are returned less often. Presumably, patients for whom this type of surgery had been chosen are also older on average or suffer from higher disease stages.

These findings are in accordance with previous research about questionnaire nonresponse in breast cancer studies. Katz et al. [28] also found that nonrespondents were more likely to have stage II disease in comparison to lower stages and to have received mastectomy compared to breast-conserving therapy. Their results stated that respondents and nonrespondents were of similar age; however, only women aged 50-79 years were included while very young and very old patients were not represented. Ahmed et al. [30] found that nonrespondents compared with respondents were more likely to be older than 62 years (study population $18-80$ years) and to have regional or distant disease spread and positive lymph nodes meaning a higher tumor stage. In contrast, in a casecontrol study conducted by Madigan et al. [31], respondents and nonrespondents appeared to be similar with respect to age; however, their study included women 20-54 years of age, so very old women were not represented. Arndt et al. [29] presented results of their breast cancer study in which respondents and nonrespondents were similar in terms of age and comorbidity status, but tumor stage was more favorable among respondents.

In previous studies among target populations other than breast cancer patients, nonresponse was associated with older or younger age and a worse health status. Christensen et al. [15] compared respondents and nonrespondents regarding morbidity and risk factor-related mortality in Denmark and found indications of a more unfavorable health behavior among nonrespondents. Melton et al. [10], just as Korkeila et al. [11] and Launer et al. [14], described nonresponse to be associated with older age, lower educational level, living alone, and worse health status. Also Rupp et al. [5] rated the probability of not responding greater for older age groups and, as well as Nummela et al. [22], Beard et al. [23], Etter and Perneger [19], and Hoeymans et al. [21], for subjects with poorer health. Van Loon et al. [13] said that response rates were found to be lower among younger people and those that live an unhealthier lifestyle and show a lower socioeconomic status. Further, in several investigations by Tolonen et al. [16-18], the stated differences were confirmed. The majority of these studies associated the differences with nonresponse bias. These findings allow us to draw parallels to the results of the present investigation.

Contradictory findings were described by van den Akker et al. [24] and Adams et al. [25] who stated that there was no difference between respondents and nonrespondents, as well as Sugisawa et al. [26] and Milne et al. [27] who even found nonrespondents to be in better health.
The scientific relevance of nonresponse effects has been frequently mentioned in connection with the limiting aspects of healthcare surveys [36-38]. Der Wiel et al. [39] confirmed that it is generally not sufficient to raise the response rate in order to avoid selection and biases. Data from nonresponse comparisons in breast cancer populations have rarely been published, so the present study contributes important knowledge on this topic. In consideration of that, this study seeks to call attention to problematic consequences of utilizing postal breast cancer survey results. In the future, further research is required to develop methods that minimize difficulties of selection bias and to ensure and optimize the quality of questionnaire survey research as a widely used scientific instrument. Further research in this field is necessary to reveal potential causes and to develop methodological adjustment processes in order to select or avoid these error sources, e.g. by case mix adjustments or emphases.

Strengths of this investigation are the relatively large sample and high response rate strengthening the representativeness of the findings and reducing random effects. Furthermore, the comparison of respondents and nonrespondents was possible because additional information about nonrespondents had been explicitly gathered by the hospital staff. This is often difficult due to limitations of available data from nonrespondents. Nonetheless, some limitations need to be considered when interpreting the study results. Firstly, the patient population was a local and specifically determined selection of the North Rhine-Westphalian breast centers. Participation was of course voluntary and raises the question of whether patients who denied participation beforehand already implied biases and error sources [40]. Unfortunately, no information was available pertaining to these patients. Volunteer research participants are known to be healthier than the general population, so the healthy volunteer effect should be mentioned as a bias source in this context $[4,41]$. The gathered information about nonrespondents does not provide an assured causal explanation for the return behavior because this paper was based on a cross-sectional study. Furthermore, the individual documentation by the hospital staff must be considered in a limitedly standardized context since this may also be prone to inaccuracies.

To conclude, in this breast cancer questionnaire survey, nonrespondents differed from respondents in age, disease stage, and general health, as well as type of surgery. Certain sample subgroups are therefore underrepresented, so that selection bias may occur. Hence, consideration must be given to the interpretation and generalizability of breast cancer survey results.

\section{Disclosure Statement}

The authors indicate no potential conflicts of interest. Costs were covered by the participating breast centers as part of the certification process. 


\section{References}

Gillham B: Developing a Questionnaire, 2nd edition. London, Continuum International Publishing Group, 2008, pp. 18-84.

2 Johnson TP, Wislar JS: Response rates and nonre sponse errors in surveys. JAMA 2012;307:1805-1806.

3 Groves RM, Fowler FJ, Couper MP, Lepkowski JM, Singer E, Tourangeau R: Survey Methodology. New York, NY, Wiley, 2004, pp. 40-243.

4 Delgado-Rodriguez M, Llorca J: Bias. J Epidemiol Community Health 2004;58:635-641.

5 Rupp I, Triemstra M, Boshuizen HC, Jacobi CE, Dinant $\mathrm{HJ}$, van den Bos GA: Selection bias due to nonresponse in a health survey among patients with rheumatoid arthritis. Eur J Public Health 2002;12:131-135

6 Ellenberg JH: Selection bias in observational and experimental studies. Stat Med 1994;13:557-567.

7 Holle R, Hochadel M, Reitmeir P, Meisinger C, Wichmann HE; KORA Group: Prolonged recruitment efforts in health surveys: effects on response, costs, and potential bias. Epidemiology 2006;17:639-643.

-8 National Research Council, Panel on a Research Agenda for the Future of Social Science Data Collection, Committee on National Statistics, Division on Behavioral and Social Science and Education; Tourangeau R, Plewes TJ (eds): Nonresponse in Social Science Surveys: A Research Agenda. Washington, DC, The National Academy Press, 2013, pp. 30-32.

$\checkmark$ Splieth CH, Steffen H, Welk A, Schwahn C: Responder and nonresponder analysis for a caries prevention program. Caries Res 2005;39:269-271.

10 Melton LJ 3rd, Dyck PJ, Karnes JL, O’Brien PC, Service FJ: Non-response bias in studies of diabetic complications: the Rochester Diabetic Neuropathy Study. J Clin Epidemiol 1993;46:341-348.

11 Korkeila K, Suominen S, Ahvenainen J, Ojanlatva A, Rautava P, Helenius H, Koskenvuo M: Non-response and related factors in a nation-wide health survey. Eur J Epidemiol 2001;17:991-999.

12 Jacobsen BK, Thelle DS: The Tromsø Heart Study: responders and non-responders to a health questionnaire, do they differ? Scand J Soc Med 1988;16:101-104.

13 Van Loon AJ, Tijhuis M, Picavet HS, Surtees PG, Ormel J: Survey non-response in the Netherlands: effects on prevalence estimates and associations. Ann Epidemiol 2003;13:105-110.

14 Launer LJ, Wind AW, Deeg DJ: Nonresponse pattern and bias in a community-based cross-sectional study of cognitive functioning among the elderly. Am J Epidemiol 1994;139:803-812.

15 Christensen AI, Ekholm O, Gray L, Glümer C, Juel K What is wrong with non-respondents? Alcohol-, drugand smoking related mortality and morbidity in a 12 year follow up study of respondents and non-respondents in the Danish Health and Morbidity Survey. Addiction 2015;110;1505-1512.

16 Tolonen H, Helakorpi S, Talala K, Helasoja V, Martelin T, Prättälä R: 25-year trends and socio-demographic differences in response rates: Finnish adult health behaviour survey. Eur J Epidemiol 2006;21:409-415.
Tolonen H, Laatikainen T, Helakorpi S, Talala K, Martelin T, Prattala R: Marital status, educational level and household income explain part of the excess mortality of survey non-respondents. Eur J Epidemiol 2010;25: 69-76.

18 Tolonen H, Dobson A, Kulathinal S; WHO MONICA Project: Effect on trend estimates of the difference between survey respondents and non-respondents: results from 27 populations in the WHO MONICA Project. Eur J Epidemiol 2005;20:887-898.

19 Etter JF, Perneger TV: Analysis of non-response bias in a mailed health survey. J Clin Epidemiol 1997;50: 1123-1128.

20 Rönmark E, Lundqvist A, Lundbäck B, Nyström L: Non-responders to a postal questionnaire on respiratory symptoms and diseases. Eur J Epidemiol 1999;15: 293-299.

21 Hoeymans N, Feskens EJ, van den Bos GA, Kromhout D: Non-response bias in a study of cardiovascular diseases, functional status and self-rated health among elderly men. Age Ageing 1998;27:35-40.

22 Nummela O, Sulander T, Helakorpi S, Haapola I, Uutela A, Heinonen H, Valve R, Fogelholm M: Register-based data indicated nonparticipation bias in a health study among aging people. J Clin Epidemiol 2011;64:1418-1425.

23 Beard CM, Lane AW, O’Fallon WM, Riggs BL, Melton LJ 3rd: Comparison of respondents and nonrespondents in an osteoporosis study. Ann Epidemiol 1994;4: 398-403.

24 Van den Akker M, Buntinx F, Metsemakers JF, Knottnerus JA: Morbidity in responders and nonresponders in a register-based population survey. Fam Pract 1998;15:261-263.

25 Adams MM, Scherr PA, Branch LG, Hebert LE, Cook NR, Lane AM, Brock DB, Evans DA, Taylor JO: A comparison of elderly participants in a community survey with nonparticipants. Public Health Rep 1990; 105:617-622.

26 Sugisawa H, Kishino H, Sugihara Y, Okabayashi H, Shibata H: Comparison of characteristics between respondents and nonrespondents in a national survey of Japanese elderly using six year follow-up study. Nihon Koshu Eisei Zasshi 1999;46:551-562.

27 Milne JS, Maule MM, Williamson J: Method of sampling in a study of older people with a comparison of respondents and non-respondents. Brit J Prev Soc Med 1971;25:37-41.

28 Katz SJ, Lantz PM, Janz NK, Fagerlin A, Schwartz K, Liu L, Deapen D, Salem B, Lakhani I, Morrow M: Patient involvement in surgery treatment decisions for breast cancer. J Clin Oncol 2005;23:5526-5533.

29 Arndt V, Merx H, Stegmaier C, Ziegler H, Brenner H: Persistence of restrictions in quality of life from the first to the third year after diagnosis in women with breast cancer. J Clin Oncol 2005;23:4945-4953.
0 Ahmed RL, Prizment A, Lazovich D, Schmitz KH, Folsom AR: Lymphedema and quality of life in breast cancer survivors: the Iowa Women's Health Study. J Clin Oncol 2008;26:5689-5696.

31 Madigan MP, Troisi R, Potischman N, Brogan D, Gammon MD, Malone KE, Brinton LA: Characteristics of respondents and non-respondents from a casecontrol study of breast cancer in younger women. Int J Epidemiol 2000;29:793-798.

32 Ferlay J, Soerjomataram I, Ervik M, Dikshit R, Eser S, Mathers C, Rebelo M, Parkin DM, Forman D, Bray F: GLOBOCAN 2012 vl.0, Cancer Incidence and Mortality Worldwide: IARC CancerBase No. 11. Lyon, International Agency for Research on Cancer, 2013. globocan.iarc.fr.

33 Pfaff H, Freise D, Mager G, Schrappe M: Der Kölner Patientenfragebogen (KPF): Entwicklung und Validierung eines Fragebogens zur Erfassung der Einbindung des Patienten als Kotherapeuten. Sankt August, Asgard-Verlag, 2003.

34 Dillmann DA: Mail and Telephone Surveys. The Total Design Method. New York, NY, Wiley, 1978.

35 Kowalski C, Würstlein R, Steffen P, Harbeck N, Pfaff $\mathrm{H}$ : Four years of surveying patients as part of the certification/re-certification of breast centers in North Rhine-Westphalia. Senologie 2010;7:24-28.

36 Miller DC, Sanda MG, Dunn RL, Montie JE, Pimentel H, Sandler HM, McLaughlin WP, Wei JT: Long-term outcomes among localized prostate cancer survivors: health-related quality-of-life changes after radical prostatectomy, external radiation, and brachytherapy. J Clin Oncol 2005;23:2772-2780.

37 Dorr DA, Jones SS, Burns L, Donelly SM, Brunker CP, Wilcox A, Clayton PD: Use of health-related, qualityof-life metrics to predict mortality and hospitalizations in community-dwelling seniors. J Am Geriatr Soc 2006;54:667-673.

38 Worthen J, Waterman BR, Davidson PA, Lubowitz $\mathrm{JH}$ : Limitations and sources of bias in clinical knee cartilage research. Arthroscopy 2012;28:1315-1325.

39 Der Wiel AB, van Exel E, de Craen AJ, Gussekloo J, Lagaay AM, Knook DL, Westendorp RG: A high response is not essential to prevent selection bias: results from the Leiden 85-plus study. J Clin Epidemiol 2002; 55:1119-1125

40 Al-Shahi R, Vousden C, Warlow C; Scottish Intracranial Vascular Malformation Study (SIVMS) Steering Committee: Bias from requiring explicit consent from all participants in observational research: prospective, population based study. BMJ 2005;331:942.

41 Friedman LM, Furberg CD, DeMets DL: Fundamentals of Clinical Trials, 4th ed. New York, NY, Springer, 2010 . 